OPEN ACCESS

Edited by:

Andreas Stengel,

Charité Universitätsmedizin Berlin,

Germany

Reviewed by:

Muriel Larauche,

University of California, Los Angeles,

United States

Karl Bechter

Universität UIm, Germany Stephan Zipfel,

Universität Tübingen, Germany

*Correspondence: Cosima Rhein

cosima.rhein@uk-erlangen.de

tThese authors have contributed equally to this work

Specialty section:

This article was submitted to

Psychosomatic Medicine,

a section of the journal

Frontiers in Psychiatry

Received: 12 February 2018

Accepted: 21 September 2018

Published: 16 October 2018

Citation:

Reichel M, Rhein C, Hofmann LM, Monti J, Japtok L, Langgartner $D$, Füchsl AM, Kleuser B, Gulbins E,

Hellerbrand $C$, Reber SO and

Kornhuber J (2018) Chronic

Psychosocial Stress in Mice Is

Associated With Increased Acid

Sphingomyelinase Activity in Liver and

Serum and With Hepatic

C16:0-Ceramide Accumulation.

Front. Psychiatry 9:496.

doi: 10.3389/fpsyt.2018.00496

\section{Chronic Psychosocial Stress in Mice Is Associated With Increased Acid Sphingomyelinase Activity in Liver and Serum and With Hepatic C16:0-Ceramide Accumulation}

\author{
Martin Reichel ${ }^{1,2}$, Cosima Rhein ${ }^{1 *}$, Lena M. Hofmann ${ }^{1}$, Juliana Monti ${ }^{1}$, Lukasz Japtok ${ }^{3}$, \\ Dominik Langgartner ${ }^{4}$, Andrea M. Füchsl ${ }^{4,5}$, Burkhard Kleuser ${ }^{3}$, Erich Gulbins ${ }^{6}$, \\ Claus Hellerbrand ${ }^{7}$, Stefan O. Reber ${ }^{4 \dagger}$ and Johannes Kornhuber ${ }^{1 \dagger}$ \\ ${ }^{1}$ Department of Psychiatry and Psychotherapy, Friedrich-Alexander-Universität Erlangen-Nürnberg, Erlangen, Germany, \\ ${ }^{2}$ Department of Nephrology and Medical Intensive Care, Charité - Universitätsmedizin Berlin, Berlin, Germany, ${ }^{3}$ Institute of \\ Nutritional Sciences, University of Potsdam, Nuthetal, Germany, ${ }^{4}$ Laboratory for Molecular Psychosomatics, Clinic for \\ Psychosomatic Medicine and Psychotherapy, University of UIm, UIm, Germany, ${ }^{5}$ Department of Internal Medicine I, \\ University Hospital Regensburg, Regensburg, Germany, ${ }^{6}$ Department of Molecular Biology, University of Duisburg-Essen, \\ Essen, Germany, ${ }^{7}$ Institute of Biochemistry, Emil-Fischer-Zentrum, Friedrich-Alexander-Universität Erlangen-Nürnberg, \\ Erlangen, Germany
}

Chronic psychosocial stress adversely affects human morbidity and is a risk factor for inflammatory disorders, liver diseases, obesity, metabolic syndrome, and major depressive disorder (MDD). In recent studies, we found an association of MDD with an increase of acid sphingomyelinase (ASM) activity. Thus, we asked whether chronic psychosocial stress as a detrimental factor contributing to the emergence of MDD would also affect ASM activity and sphingolipid (SL) metabolism. To induce chronic psychosocial stress in male mice we employed the chronic subordinate colony housing (CSC) paradigm and compared them to non-stressed single housed control (SHC) mice. We determined Asm activity in liver and serum, hepatic SL concentrations as well as hepatic mRNA expression of genes involved in SL metabolism. We found that hepatic Asm activity was increased by $28 \%(P=0.006)$ and secretory Asm activity by $47 \%$ $(P=0.002)$ in stressed mice. C16:0-Cer was increased by $40 \%(P=0.008)$. Gene expression analysis further revealed an increased expression of tumor necrosis factor (TNF)- $\alpha(P=0.009)$ and of several genes involved in SL metabolism (Cers5, $P=0.028$; Cers6, $P=0.045$; Gba, $P=0.049$; Gba2, $P=0.030$; Ormdl2, $P=0.034$; Smpdl3B; $P=0.013)$. Our data thus provides first evidence that chronic psychosocial stress, at least in mice, induces alterations in SL metabolism, which in turn might be involved in mediating the adverse health effects of chronic psychosocial stress and peripheral changes occurring in mood disorders.

Keywords: chronic psychosocial stress, acid sphingomyelinase, ceramide, sphingolipid metabolism, chronic subordinate colony housing (CSC), liver metabolism 


\section{INTRODUCTION}

Stress, defined as the physiological response of the body to any demand (1), serves the principal goal to mobilize energy for appropriate, fight or flight' response. The primary response includes the activation of the sympathetic nervous system and the hypothalamus-pituitary-adrenal axis, resulting in the secretion of catecholamines and glucocorticoids from the adrenal gland. Albeit this adaptation promotes survival of physical threats to homeostasis, chronic psychosocial threats are well-known to adversely affect human health (2-4).

Chronic psychosocial stress, particularly in conjunction with viral hepatitis, cirrhosis, and hepatocellular carcinoma is thought to contribute to the development and progression of liver disease (5). For instance, a comparison of the mortality in the general population between periods of economic crisis and periods prior or after the crisis revealed an increased all-cause mortality, due among others to an increased incidence of chronic liver disease (3). Moreover, chronic stress is a well-known risk factor for the development of obesity and metabolic syndrome (6, 7). Animal studies further support the hypothesis that chronic stress induces (8) and aggravates $(9,10)$ liver injury, causes hepatic oxidative stress $(11,12)$ and insulin resistance (13), alters hepatic metabolism and gene transcription (14), and disrupts the regulation of lipid synthesis (15).

Sphingolipids (SL) comprise a class of lipids with important structural functions and relevance in cell signaling (16). Bioactive SL play a role in the regulation of cell growth, death, senescence, adhesion, migration, inflammation, angiogenesis, and intracellular trafficking (17). Ceramides (Cer) constitute a family of lipid species (18) that are central to SL metabolism as they serve as precursors for the biosynthesis of plasma membrane SL such as glycosphingolipids (GSL) or sphingomyelins (SM), and, alternatively, can be metabolized into other bioactive SL such as ceramide-1-phoshate, sphingosine, and sphingosine-1phosphate. Additionally, Cer modulate a number of biochemical and cellular processes induced by stressor exposure, including apoptosis, cell-cycle arrest and cell senescence. Moreover, several extracellular challenges, such as tumor necrosis factor (TNF)$\alpha$, chemotherapeutic agents and heat, cause Cer accumulation (19). Increased Cer levels, in turn, are supposed to contribute to the development of several human diseases, including liver diseases (20). Cer can be synthesized de novo from serine and palmitoyl-CoA or by re-acylation of sphingosine in a salvage pathway. Cer can be also generated by the breakdown of SL from biological membranes. Acid sphingomyelinase (here referred to as ASM for human protein and Asm for mouse protein) is one of several mammalian sphingomyelinases that catalyzes the breakdown of SM to Cer and phosphorylcholine (21). Activity of ASM is sensitive to cellular stress and is activated, among others, by TNF- $\alpha$ (22), oxidative stress (23), and ionizing radiation (24). In line with these findings, recent studies provided evidence that both stress-associated disorders, as for instance major depression (25), chronic heart failure (26), acute and chronic alcohol consumption $(27,28)$, and chronic hepatitis C infection (29), as well as various chronic unpredictable stressors $(25,30)$, have been associated with increased ASM activity and Cer levels, respectively.
However, it is unknown to date whether this holds true for chronic stressors which are psychosocial in nature. We therefore analyzed mice subjected to the chronic subordinate colony housing (CSC) paradigm, a pre-clinically validated mouse model for chronic psychosocial stress (31). Importantly, besides typical stress symptoms such as adrenal hypertrophy, thymus atrophy, and increased plasma nor-epinephrine levels, CSC exposure reliably causes anxiety and spontaneous colitis, increases the risk for colon cancer (32), and induces hepatic inflammation and oxidative stress (11). Our analysis of serum samples and liver specimen revealed that chronic psychosocial stress is associated with increased Asm activity, increased levels of C16:0-Cer, a decline in C24:0-Cer, and increased expression levels of Cers5, Cers6, Gba, Gba2, Ormdl2, and Smpdl3b mRNA. Thus, a shift in the SL composition toward an accumulation of C16:0-Cer might be the origin of the adverse health effects associated with chronic psychosocial stress.

\section{METHODS}

\section{Animal Specimens}

Liver and serum specimens of male C57BL/6 mice (Charles River, Sulzfeld, Germany) that were either exposed to CSC $(n=8)$ for 19 days or kept as SHC $(n=8)$ were analyzed. Animals and procedures are described in detail in Czech et al. (11). Briefly, four CSC mice were housed together with a larger dominant male in a polycarbonate observation cage $(38 \times 22 \times 35 \mathrm{~cm})$ for $19 \mathrm{~d}$ consecutively. Prior to CSC exposure, all potential male dominant mice were tested for their aggressive behavior. Males that started to injure their opponents by harmful bites were not used for the CSC procedure. To avoid habituation, each dominant male was replaced by a novel dominant male on days 8 and 15 . Serum of independent CSC and SHC groups (each $n=8$ ) was used to confirm results. All experimental protocols were approved by the Committee on Animal Health and Care of the Government of Oberpfalz (Permit Number: 54-2531.2-16/08) and conform to international guidelines on the ethical use of animals.

\section{Preparation of Tissue Lysates and Determination of Asm Activity}

Asm activity was determined from liver homogenates and from serum. Tissue, homogenates and serum were stored at $-80^{\circ} \mathrm{C}$ prior to the analysis. For the preparation of liver homogenates, pieces of $10-20 \mathrm{mg}$ tissue were homogenized in $0.5 \mathrm{ml}$ sucrose lysis buffer ( $250 \mathrm{mM}$ sucrose, $1 \mathrm{mM}$ EDTA, $0.2 \%$ Triton X-100) using a TissueLyser LT bead mill (Qiagen). Raw lysates were centrifugated with $\geq 10,000 \mathrm{~g}$ at $4{ }^{\circ} \mathrm{C}$ for $10 \mathrm{~min}$, and supernatants were transferred to new tubes. The protein concentrations were determined using bicinchoninic acid kit (Sigma). For the determination of Asm activity from liver homogenates, $1 \mu \mathrm{g}$ of protein were incubated with $0.58 \mu \mathrm{M}$ $\mathrm{N}$-(4,4-difluoro-5,7-dimethyl-4-bora-3a,4a-diaza-s-indacene3-dodecanoyl)-sphingosylphosphocholine $\quad$ (BODIPY ${ }^{\circledR} \quad \mathrm{FL}$ $\mathrm{C}_{12}$-sphingomyelin; D-7711; Life Technologies, Darmstadt, Germany) in $50 \mu \mathrm{l}$ reaction buffer $(50 \mathrm{mM}$ sodium acetate $\mathrm{pH}$ $5.0,0.3 \mathrm{M} \mathrm{NaCl}, 0.2 \% \mathrm{NP}-40$ ) for $2 \mathrm{~h}$ at $37^{\circ} \mathrm{C}$; after incubation, 
$3 \mu \mathrm{l}$ of the reaction volume was spotted on a silica gel 60 plate (Macherey-Nagel; Düren, Germany), and Cer and SM were separated by thin layer chromatography using $99 \%$ ethyl acetate $/ 1 \%$ acetic acid (v/v) as a solvent (33). Intensity of BODIPY-conjugated Cer and SM fractions were determined using a Typhoon Trio scanner (GE Healthcare, München, Germany) and quantified with QuantityOne software (Biorad, München, Germany). For each liver specimen, Asm activity was determined twice from two independent pieces of tissue with similar results. Activity of secretory (S-) Asm was measured with the same protocol using $2 \mu \mathrm{l}$ of serum and with additional $500 \mu \mathrm{M} \mathrm{ZnCl}_{2}$ in the reaction buffer.

\section{Quantification of Ceramide and Sphingomyelin Species by Mass Spectrometry}

Cer and SM were extracted and quantified as described previously (25). Briefly, lipid extraction was performed from $100 \mu \mathrm{l}$ liver homogenates containing $50 \mu \mathrm{g}$ total protein using C17:0-Cer and deuterated C16-d31 SM (N-palmitoyld31-D-erythro-sphingomyelin; Avanti Polar Lipids) as internal standards. Sample analysis was carried out by rapid-resolution liquid chromatography-MS/MS using a Q-TOF 6,530 mass spectrometer (Agilent Technologies, Waldbronn, Germany) operating in the positive ESI mode. The precursor ions of Cer species [C16:0-Cer (m/z 520.508), C17:0-Cer (m/z 534.524), C18:0-Cer (m/z 548.540), C20:0-Cer (m/z 576.571), C22:0Cer (m/z 604.602), C24:0-Cer (m/z 632.634), C24:1-Cer (m/z 630.618)] were cleaved into the fragment ion $\mathrm{m} / \mathrm{z}$ 264.270. The precursor ions of SM species [C16:0-SM (m/z 703.575), C16d31 SM (m/z 734.762), C18:0-SM (m/z 731.606), C20:0-SM (m/z 759.638), C22:0-SM (m/z 787.669), C24:0-SM (m/z 815.700), C24:1-SM (m/z 813.684)] were cleaved into the fragment ion $\mathrm{m} / \mathrm{z}$ 184.074. Quantification was performed with Mass Hunter Software (Agilent Technologies).

\section{Extraction of RNA and Synthesis of cDNA}

Total RNA was isolated from pieces of liver tissues (<30 mg) using a TissueLyser LT bead mill (Qiagen) and peqGOLD Trifast reagent (Peqlab, Erlangen, Germany) according to manufacturers' instructions. RNA qualities and concentrations were assessed using a Nanodrop ND-1000 UV-Vis spectrophotometer. SuperScript VILO cDNA synthesis kit (Invitrogen) was used to reverse transcribe $1 \mu \mathrm{g}$ RNA into cDNA using $2 \mu 15 \mathrm{x}$ VILO reaction mix and $1 \mu 1$ 10x SuperScript enzyme mix in a final volume of $10 \mu \mathrm{l}$. After completion and termination of the RT reaction, cDNA was diluted with $190 \mu \mathrm{l}$ LowTE and stored at $-20^{\circ} \mathrm{C}$.

\section{Quantitative PCR Analysis}

Quantitative real-time PCR was performed using a LightCycler 480 real-time PCR system (Roche, Germany) and SYBR-green chemistry. In detail, qPCR reactions contained $5 \mu \mathrm{l}$ FastStart Essential DNA Green Master, $1 \mu \mathrm{M}$ of each primer and 2.5 $\mu l$ diluted cDNA (corresponding to $12.5 \mathrm{ng}$ RNA) in a total volume of $10 \mu \mathrm{l}$. Temperature profile used was: $95^{\circ} \mathrm{C}$ for $5 \mathrm{~min}$ followed by 45 cycles of amplification $\left(95^{\circ} \mathrm{C}\right.$ for $10 \mathrm{~s}, 60^{\circ} \mathrm{C}$ for
$20 \mathrm{~s}, 72^{\circ} \mathrm{C}$ for $30 \mathrm{~s}$ ) and by melting curve analysis. After run, PCR product specificity was assessed by the inspection of single peak melting curves, and threshold cycles $(\mathrm{Ct})$ were determined with the second derivative maximum method using the LightCycler 480 software (release 1.5.0). Gene-specific primers were either selected from the literature or from PrimerBank (https://pga. mgh.harvard.edu/primerbank/) or designed via the Universal Probe Library Assay Design Center (http://qpcr.probefinder. com/organism.jsp). Reference genes were tested and selected according to their gene expression stability (34), and a normalization factor was calculated based on the geometric mean of the reference genes Rpl32, Rpl38, Hprt, and Gusb (34) using the SLqPCR package in $\mathrm{R}$ version 3.2.2. Relative mRNA expression levels were calculated in Microsoft Excel using the $2^{-\Delta \Delta C t}$ method (35). The sequence of primers is given in Table 1 .

\section{Statistical Analyses}

Statistical analyses were performed using the IBM SPSS Statistics version 21. Continuous variables were tested for deviation from normal distributions using the Kolmogorov-Smirnov test. Statistical significance of measurements between SHC and CSC mice was determined using ANOVA. A two-sided $P<0.05$ was considered to indicate statistical significance. All results are presented as mean value \pm standard deviation (SD). Graphs were created with GraphPad Prism for Windows, Version 4.01 (Graphpad Software, LaJolla, CA) or with MS Excel 2010.

\section{RESULTS}

\section{Asm Activities Are Elevated in Stressed Mice}

Hepatic Asm activity in CSC mice was increased by $28 \%$ in comparison to SHC mice (Figure 1A; relative Asm activity in SHC: $1.00 \pm 0.18, n=8$; CSC: $1.28 \pm 0.17, n=8 ; P=0.006)$. We also determined activity of S-Asm in serum. S-Asm activity of CSC mice was increased by $57 \%$ (Figure 1B; relative S-Asm activity in SHC: $1.00 \pm 0.34, n=16$; CSC: $1.57 \pm 0.37, n=14$; $P=0.0001)$.

\section{Stressed Mice Display Higher Percentage of C16:0-Ceramide}

Hepatic tissue was subjected to lipidomic analyses to determine Cer and SM content. Total Cer (SHC: $643 \pm 63.4 \mathrm{pmol} / \mathrm{mg}$ protein, $n=8$; CSC: $640 \pm 68.9 \mathrm{pmol} / \mathrm{mg}$ protein, $n=8$; $P=0.927$ ) and SM levels (SHC: $2,320 \pm 239 \mathrm{pmol} / \mathrm{mg}$ protein, $n=8$; CSC: $2.677 \pm 440 \mathrm{pmol} / \mathrm{mg}$ protein, $n=8$; $P=0.064)$ were not increased in CSC mice. To assess the relative composition of the hepatic Cer pool, we calculated the relative percentage for every single species. The composition of the Cer pool was changed significantly in response to stress toward a higher percentage of long chain C16:0-Cer (from 13.5 to $18.8 \%$, $P=0.017)$ and a lower percentage of Cer species with verylong saturated acyl chains (C22:0-Cer: 29.2 to $26.2 \%, P=0.127$; C24:0-Cer: 27.8 to $25.1 \%, P=0.033$ ) (Figure 2). 
TABLE 1 | Sequence of primers used in this study.

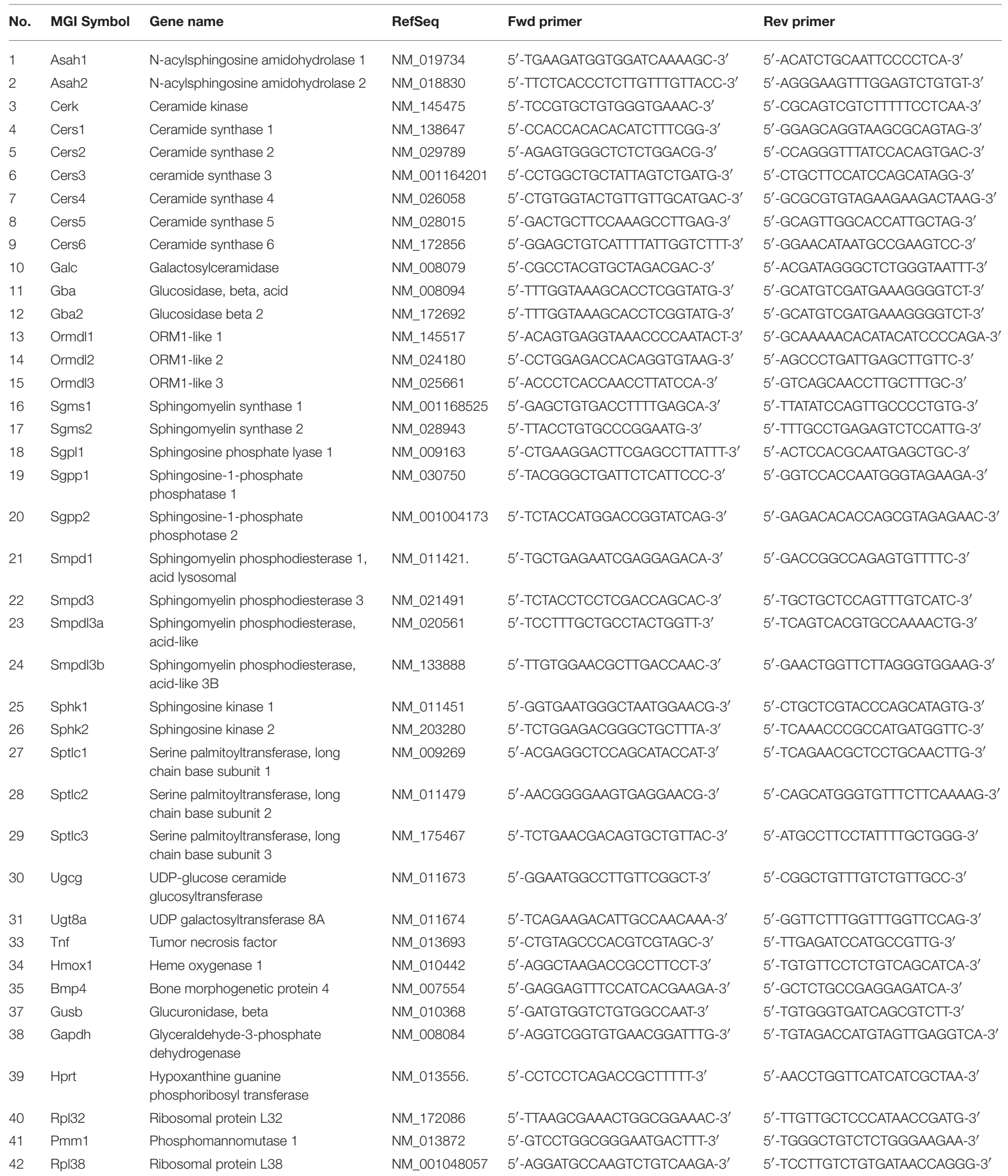




\section{TNF- $\alpha$ mRNA Expression Is Upregulated in CSC Mice}

We further analyzed TNF- $\alpha$ mRNA expression levels in liver tissue. In agreement with a previous report (11), TNF- $\alpha$ mRNA was significantly increased in CSC compared to controls (SHC: $1.00 \pm 0.42, n=8$; CSC: $2.43 \pm 1.15, n=8 ; P=0.009)$.

\section{RNA Expression of SL Metabolizing Enzymes Is Upregulated in CSC Mice}

To check if other pathways in addition to the SM hydrolyzing pathway via Asm were involved in the change of C16:0-Cer levels upon chronic psychosocial stress, we conducted a gene expression analysis of 31 genes involved in the metabolism of Cer in liver tissue (Table 1). Three genes, ceramide synthase 1 (Cers1), ceramide synthase 3 (Cers3), and serine palmitoyltransferase, long chain base subunit 3 (Sptlc3) were not expressed in hepatic tissue (data not shown). A comparison of the normalized mRNA
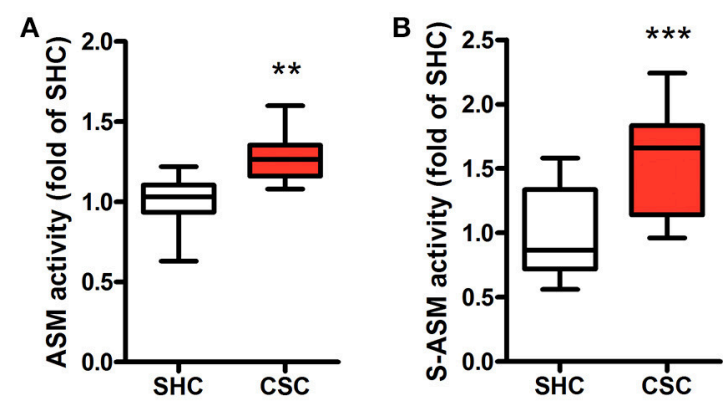

FIGURE 1 | Chronic psychosocial stress is associated with increased Asm activity in liver and serum. Asm activity in liver (A) and serum (B) of SHC and CSC mice (each $n=8$ for liver and $n=16$ for serum). For ease of comparison, activities of SHC mice was set to 1. Data are presented as mean values $\pm S D$. Asterisks indicate statistical significance CSC vs. SHC ${ }^{* \star} p<0.01$,

$\left.{ }^{\star \star \star} p<0.0001\right)$. CSC, chronic subordinate colony housing; SHC, single housed controls.

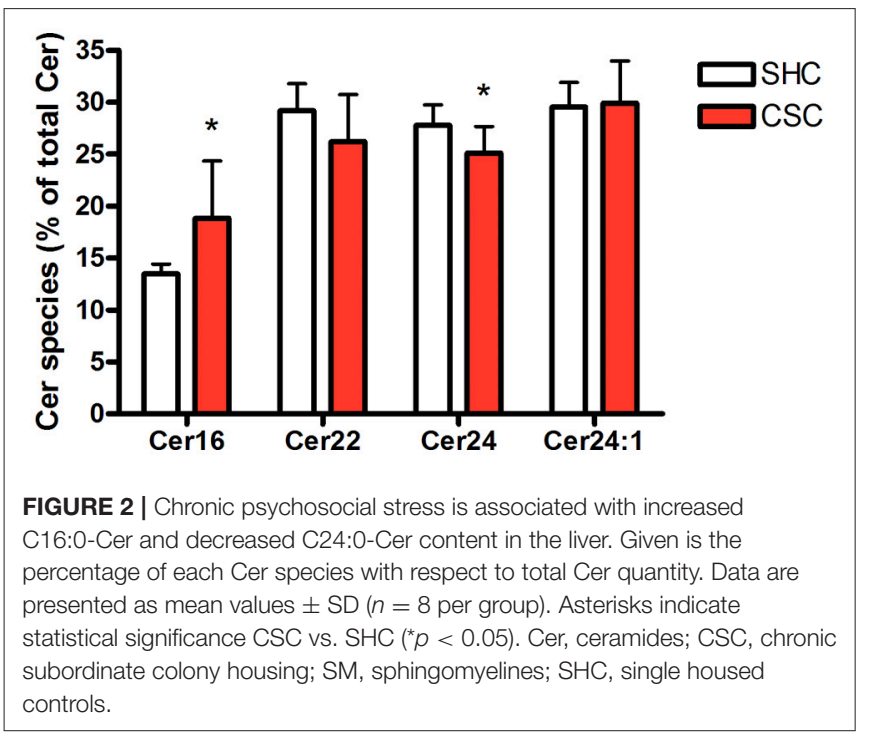

expression levels of the other 28 genes revealed that the majority was higher expressed in CSC compared to SHC mice (Table 2). Cers5, Cers6, Gba, Gba2, Ormdl2, and Smpdl3b mRNA were significantly higher expressed in CSC mice compared to control mice (Figure 3).

\section{DISCUSSION}

In this study, we showed for the first time that chronic psychosocial stress in mice leads to the activation of Asm and, consequently, increased Cer levels, both assessed in hepatic tissue. In detail, increased Asm activity in mice exposed to chronic psychosocial stress was associated with increased concentration of C16:0-Cer and a decline of C24:0-Cer. Increased C16:0-Cer concentrations and especially a shift from very-longchain C24:0-Cer to long chain C16:0-Cer in the SL composition is frequently observed (36) and confers susceptibility to cellular apoptosis (37) and steatohepatitis and insulin resistance (38). Thus, activation of Asm seems likely to constitute an important link between chronic psychosocial stress and its adverse health effects in the liver, but also in other organs.

TABLE 2 | Gene expression analysis of genes involved in SL metabolism.

\begin{tabular}{lcc}
\hline MGI symbol & Change (\%) & $\boldsymbol{P}$-value \\
\hline Asah1 & 3.88 & 0.719 \\
Asah2 & -11.2 & 0.423 \\
Cerk & 16.1 & 0.297 \\
Cers2 & -25.2 & 0.162 \\
Cers4 & -11.6 & 0.554 \\
Cers5 & $\mathbf{3 5 . 9}$ & $\mathbf{0 . 0 2 8}$ \\
Cers6 & $\mathbf{6 6 . 9}$ & $\mathbf{0 . 0 4 5}$ \\
Galc & 16.9 & 0.162 \\
Gba & $\mathbf{2 8 . 9}$ & $\mathbf{0 . 0 4 9}$ \\
Gba2 & $\mathbf{3 9 . 7}$ & $\mathbf{0 . 0 3 0}$ \\
Sgms1 & 20.7 & 0.198 \\
Sgms2 & -4.79 & 0.756 \\
Sgpl1 & -0.85 & 0.965 \\
Sgpp1 & -1.88 & 0.911 \\
Sgpp2 & 11.7 & 0.656 \\
Smpd1 & 32.8 & 0.075 \\
Smpd3 & 90.5 & 0.130 \\
Sphk1 & 24.5 & 0.385 \\
Sphk2 & -11.4 & 0.315 \\
Sptlc1 & 24.0 & 0.086 \\
Sptlc2 & 49.7 & 0.052 \\
Ugcg & 18.3 & 0.220 \\
Ugt8a & -2.95 & 0.879 \\
Ormdl1 & 0.95 & 0.954 \\
Ormdl2 & $\mathbf{3 9 . 9}$ & 0.984 \\
Ormdl3 & $\mathbf{0 . 3 2}$ & 0.344 \\
Smpdl3a & $\mathbf{0 . 0 1 3}$ \\
Smpdl3b & & \\
\hline Sin & & \\
\hline
\end{tabular}

Significance of differentially expressed genes under chronic psychosocial stress was estimated using t-test. Genes with $P<0.05$ are given in bold. 

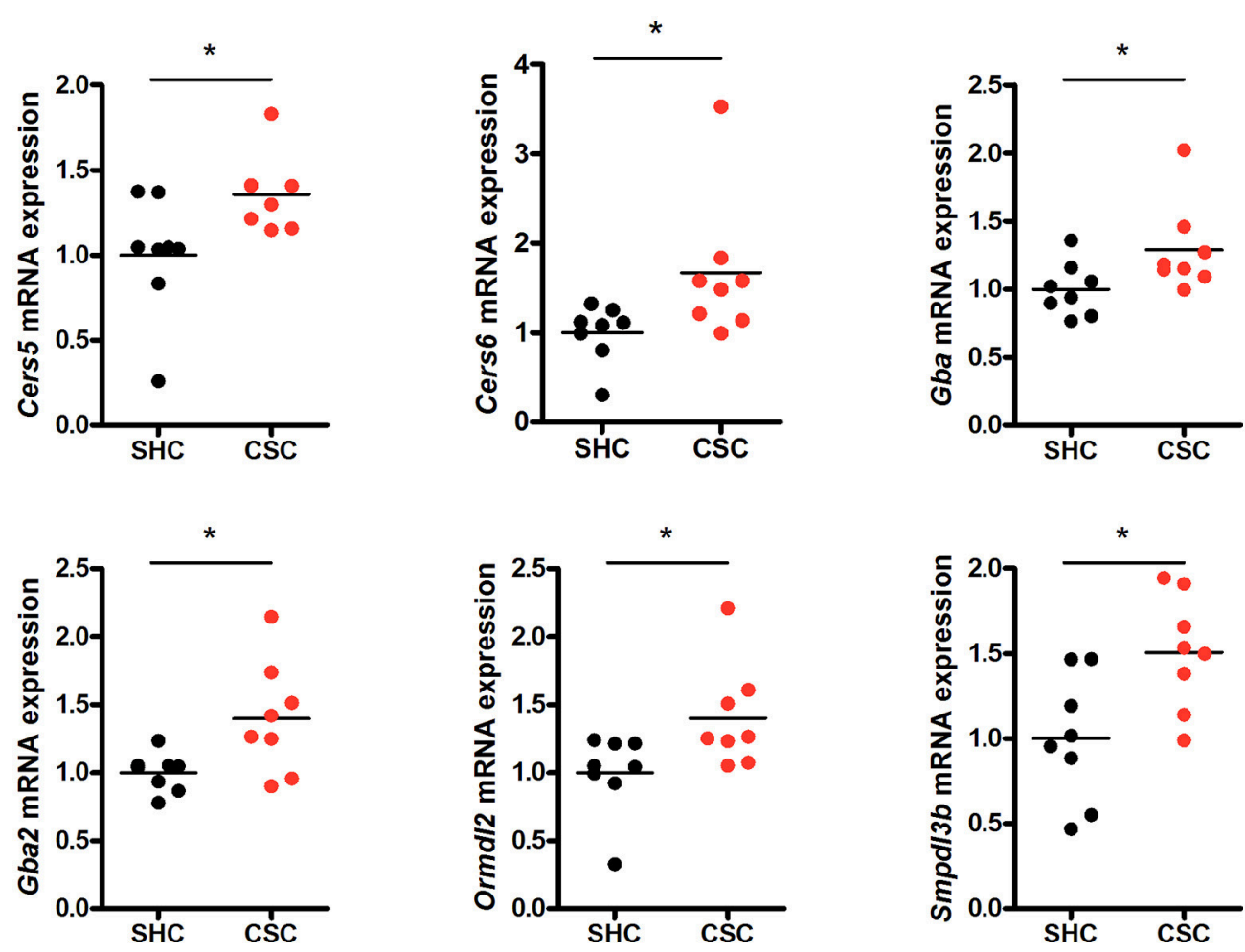

FIGURE 3 | Chronic psychosocial stress is associated with altered gene expression in the liver of enzymes regulating ceramide production. Relative mRNA expression of genes involved in sphingolipid metabolism. Vertical scatter plot of genes differentially expressed in CSC vs. SHC (t-tests, $P<0.05)$. Selection of reference genes and calculation of the normalization factor was conducted according to Vandesompele et al. (34). For ease of comparison, transcript level in SHC mice was set to 1. Asterisks indicate statistical significance CSC vs. SHC ( $\left.{ }^{*} p<0.05\right)$. CSC, chronic subordinate colony housing; SHC, single housed controls.

Our analysis further revealed that chronic psychosocial stress affects other key aspects of sphingolipid regulation besides activation of ASM. By means of gene expression analysis we found that several enzymes involved in SL metabolism-Cers5 and Cers6, Gba, Gba2, Ormdl2, and Smpdl3b-were upregulated under conditions of chronic psychosocial stress. Ceramide synthase (CerS) 5 and 6 (MGI symbol Cers5 and Cers6) belong to a group of enzymes that catalyze the formation of ceramides by $N$-acylation of sphingoid bases. Each CerS has a high specificity toward the acyl chain length and, thus, the active CerS isozymes determine the fatty acid composition of Cer and the derived SL (39). Of the six mammalian CerSs we found four-CerS2, CerS4, CerS5, and CerS6-to be expressed in hepatic mouse tissue, while we could not detect transcripts of CerS1 or CerS3. These results are in line with a previous report (40). Increased CerS5 or CerS6 activity can mediate the accumulation of C16:0-Cer $(41,42)$. Of note, several reports indicate that CerS6 activity is controlled via transcriptional regulation (42, 43). Thus, increased expression of CerS5 and CerS6 following chronic psychosocial stress might be responsible for the shift in the cellular SL composition from very-long-chain Cer to long-chain C16-Cer and, thus, contribute to the adverse health effect of stress. However, since CerS are also regulated by posttranslational mechanisms $(44,45)$, enzymatic activities of CerS5 and CerS6 under conditions of chronic psychosocial stress should to be determined before claiming a role in stress-induced health issues.

We also found two glucosylceramidases, Gba and Gba2, to be transcriptionally upregulated under chronic psychosocial stress. This could also contribute to increased Cer levels, resulting from the hydrolysis of glucosylceramide. Chronic psychosocial stress also induced increased expression Ormdl2. Ormdl2 belongs to the evolutionarily conserved family of ORM-like proteins, which are central regulators of SL metabolism (46). Ormdl proteins are negative regulators of de novo ceramide synthesis via inhibition of serine palmitoyltransferase (SPTLC), the first and rate-limiting enzyme in SL production. However, Ormdl proteins can also stimulate de novo synthesis of complex SL downstream of SPTLC in yeast (47) via a mechanism that potentially involves CerS activity (48). Sphingomyelinase-like phosphodiesterase 3b (MGI symbol: $S m p d l 3 b$ ) is a GPI-anchored SM phosphodiesterase with relevance for cellular lipid composition (49). Knockdown of Smpdl3b in RAW264.7 macrophages results in decreased Cer level, indicating that the protein acts as an enzyme and generates Cer.

In summary, our analysis provides first evidence that chronic psychosocial stress has an impact on the hepatic SL metabolism in mice. Whether this relates to the primary stress response, e.g., secretion of glucocorticoids and catecholamines,-not mutually exclusively-or to the strong connection of SL with inflammation 
and oxidative stress (50) needs to be determined in future studies. Similar changes of the SL metabolism might be involved in the development of stress-associated pathologies in humans, and key enzymes of SL metabolism such as ASM (51) and CerS6 (52) might constitute therapeutic targets to prevent or treat such conditions.

\section{AUTHOR CONTRIBUTIONS}

MR and SR conceived and designed the experiments. MR and CR wrote the manuscript. MR, LH, JM, LJ, BK, DL, and

\section{REFERENCES}

1. Selye H. Stress without distress. In: Serban G. editor. Psychopathology of Human Adaptation. Boston, MA: Springer (1976). p. 137-46.

2. Brunner EJ. Social factors and cardiovascular morbidity. Neurosci Biobehav Rev. (2017) 74(Pt B):260-8. doi: 10.1016/j.neubiorev.2016.05.004

3. Falagas ME, Vouloumanou EK, Mavros MN, Karageorgopoulos DE. Economic crises and mortality: a review of the literature. Int J Clin Pract. (2009) 63:1128-35. doi: 10.1111/j.1742-1241.2009.02124.x

4. Prior A, Fenger-Gron M, Larsen KK, Larsen FB, Robinson KM, Nielsen MG, et al. The association between perceived stress and mortality among people with multimorbidity: a prospective population-based cohort study. Am J Epidemiol. (2016) 184:199-210. doi: 10.1093/aje/kwv324

5. Vere CC, Streba CT, Streba LM, Ionescu AG, Sima F. Psychosocial stress and liver disease status. World J Gastroenterol. (2009) 15:2980-6. doi: 10.3748 /wjg. 15.2980

6. Nieuwenhuizen AG, Rutters F. The hypothalamic-pituitary-adrenal-axis in the regulation of energy balance. Physiol Behav. (2008) 94:169-77. doi: 10.1016/j.physbeh.2007.12.011

7. Tamashiro KL, Sakai RR, Shively CA, Karatsoreos IN, Reagan LP. Chronic stress, metabolism, and metabolic syndrome. Stress (2011) 14:468-74. doi: $10.3109 / 10253890.2011 .606341$

8. Fernandez G, Mena MP, Arnau A, Sanchez O, Soley M, Ramirez I. Immobilization stress induces c-Fos accumulation in liver. Cell Stress Chaperones (2000) 5:306-12.

9. Chida Y, Sudo N, Sonoda J, Sogawa H, Kubo C. Electric foot shock stress-induced exacerbation of alpha-galactosylceramide-triggered apoptosis in mouse liver. Hepatology (2004) 39:1131-40. doi: 10.1002/hep.20158

10. Sonoda J, Chida Y, Sudo N, Kubo C. Social disruption stress exacerbates alphagalactosylceramide-induced hepatitis in mice. Neuroimmunomodulation (2005) 12:375-9. doi: 10.1159/000091131

11. Czech B, Neumann ID, Müller M, Reber SO, Hellerbrand C. Effect of chronic psychosocial stress on nonalcoholic steatohepatitis in mice. Int J Clin Exp Pathol. (2013) 6:1585-93.

12. Duda W, Curzytek K, Kubera M, Iciek M, Kowalczyk-Pachel D, BilskaWilkosz A, et al. The effect of chronic mild stress and imipramine on the markers of oxidative stress and antioxidant system in rat liver. Neurotox Res. (2016) 30:173-84. doi: 10.1007/s12640-016-9614-8

13. Sanghez V, Cubuk C, Sebastian-Leon P, Carobbio S, Dopazo J, VidalPuig A, et al. Chronic subordination stress selectively downregulates the insulin signaling pathway in liver and skeletal muscle but not in adipose tissue of male mice. Stress (2016) 19:214-24. doi: 10.3109/10253890.2016. 1151491

14. Jia HM, Li Q, Zhou C, Yu M, Yang Y, Zhang HW, et al. Chronic unpredictive mild stress leads to altered hepatic metabolic profile and gene expression. Sci Rep. (2016) 6:23441. doi: 10.1038/srep23441

15. Chuang JC, Cui H, Mason BL, Mahgoub M, Bookout AL, Yu HG, et al. Chronic social defeat stress disrupts regulation of lipid synthesis. J Lipid Res. (2010) 51:1344-53. doi: 10.1194/jlr.M002196

16. Van MG, Voelker DR, Feigenson GW. Membrane lipids: where they are and how they behave. Nat Rev Mol Cell Biol. (2008) 9:112-24. doi: $10.1038 / \mathrm{nrm} 2330$
AF performed experiments. MR, CR, JK, and EG analyzed the data. $\mathrm{CH}$ contributed reagents, materials, and analysis tools. EG and JK provided funding. All authors reviewed the manuscript.

\section{ACKNOWLEDGMENTS}

The authors are grateful to N. Grunwald for excellent technical support. This study was supported by DFG grants GU 335/29-1 to EG and KO 947/13-1 to JK and BMBF grants 01EE1401G to EG and 01EE1401C to JK.

17. Hannun YA, Obeid LM. Principles of bioactive lipid signalling: lessons from sphingolipids. Nat Rev Mol Cell Biol. (2008) 9:139-50. doi: 10.1038/nrm2329

18. Hannun YA, Obeid LM. Many ceramides. J Biol Chem. (2011) 286:27855-62. doi: 10.1074/jbc.R111.254359

19. Hannun YA, Luberto C. Ceramide in the eukaryotic stress response. Trends Cell Biol. (2000) 10:73-80. doi: 10.1016/S0962-8924(99)01694-3

20. Pagadala M, Kasumov T, McCullough AJ, Zein NN, Kirwan JP. Role of ceramides in nonalcoholic fatty liver disease. Trends Endocrinol Metab. (2012) 23:365-71. doi: 10.1016/j.tem.2012.04.005

21. Jenkins RW, Canals D, Hannun YA. Roles and regulation of secretory and lysosomal acid sphingomyelinase. Cell Signal. (2009) 21:836-46. doi: 10.1016/j.cellsig.2009.01.026

22. Schütze S, Potthoff K, Machleidt T, Berkovic D, Wiegmann K, Krönke M. TNF activates NF-kappa B by phosphatidylcholine-specific phospholipase C-induced "acidic" sphingomyelin breakdown. Cell (1992) 71:765-76. doi: 10.1016/0092-8674(92)90553-O

23. Castillo SS, Levy M, Wang C, Thaikoottathil JV, Khan E, Goldkorn T. Nitric oxide-enhanced caspase- 3 and acidic sphingomyelinase interaction: a novel mechanism by which airway epithelial cells escape ceramideinduced apoptosis. Exp Cell Res. (2007) 313:816-23. doi: 10.1016/j.yexcr.2006. 12.001

24. Santana P, Pena LA, Haimovitz-Friedman A, Martin S, Green D, McLoughlin $\mathrm{M}$, et al. Acid sphingomyelinase-deficient human lymphoblasts and mice are defective in radiation-induced apoptosis. Cell (1996) 86:189-99. doi: 10.1016/S0092-8674(00)80091-4

25. Gulbins E, Palmada M, Reichel M, Lüth A, Bohmer C, Amato D, et al. Acid sphingomyelinase-ceramide system mediates effects of antidepressant drugs. Nat Med. (2013) 19:934-8. doi: 10.1038/nm.3214

26. Doehner W, Bunck AC, Rauchhaus M, von Haehling S, Brunkhorst FM, Cicoira M, et al. Secretory sphingomyelinase is upregulated in chronic heart failure: a second messenger system of immune activation relates to body composition, muscular functional capacity, and peripheral blood flow. Eur Heart J. (2007) 28:821-8. doi: 10.1093/eurheartj/ehl541

27. Reichel M, Greiner E, Richter-Schmidinger T, Yedibela O, Tripal P, Jacobi A, et al. Increased acid sphingomyelinase activity in peripheral blood cells of acutely intoxicated patients with alcohol dependence. Alcohol Clin Exp Res. (2010) 34:46-50. doi: 10.1111/j.1530-0277.2009.01064.x

28. Reichel M, Beck J, Mühle C, Rotter A, Bleich S, Gulbins E, et al. Activity of secretory sphingomyelinase is increased in plasma of alcohol-dependent patients. Alcohol Clin Exp Res. (2011) 35:1852-9. doi: 10.1111/j.1530-0277.2011.01529.x

29. Grammatikos G, Mühle C, Ferreiros N, Schroeter S, Bogdanou D, Schwalm $\mathrm{S}$, et al. Serum acid sphingomyelinase is upregulated in chronic hepatitis $\mathrm{C}$ infection and non alcoholic fatty liver disease. Biochim Biophys Acta (2014) 1841:1012-20. doi: 10.1016/j.bbalip.2014.04.007

30. Oliveira TG, Chan RB, Bravo FV, Miranda A, Silva RR, Zhou B, et al. The impact of chronic stress on the rat brain lipidome. Mol Psychiatry (2016) 21:80-8. doi: $10.1038 / \mathrm{mp} .2015 .14$

31. Reber SO, Birkeneder L, Veenema AH, Obermeier F, Falk W, Straub RH, et al. Adrenal insufficiency and colonic inflammation after a novel chronic psychosocial stress paradigm in mice: implications and mechanisms. Endocrinology (2007) 148:670-82. doi: 10.1210/en.2006-0983 
32. Langgartner D, Füchsl AM, Uschold-Schmidt N, Slattery DA, Reber SO. Chronic subordinate colony housing paradigm: a mouse model to characterize the consequences of insufficient glucocorticoid signaling. Front Psychiatry (2015) 6:18. doi: 10.3389/fpsyt.2015.00018

33. Mühle C, Kornhuber J. Assay to measure sphingomyelinase and ceramidase activities efficiently and safely. J ChromatogrA (2017) 1481:137-44. doi: 10.1016/j.chroma.2016.12.033

34. Vandesompele J, De Preter K, Pattyn F, Poppe B, Van Roy N, De Paepe A, et al. Accurate normalization of real-time quantitative RT-PCR data by geometric averaging of multiple internal control genes. Genome Biol. (2002) 3:RESEARCH0034. doi: 10.1186/gb-2002-3-7-research0034

35. Schmittgen TD, Livak KJ. Analyzing real-time PCR data by the comparative C(T) method. Nat Protoc. (2008) 3:1101-8. doi: 10.1038/nprot. 2008.73

36. Pewzner-Jung Y, Park H, Laviad EL, Silva LC, Lahiri S, Stiban J, et al. A critical role for ceramide synthase 2 in liver homeostasis: I. Alterations in lipid metabolic pathways. J Biol Chem. (2010) 285:10902-10. doi: 10.1074/jbc.M109.077594

37. Sassa T, Suto S, Okayasu Y, Kihara A. A shift in sphingolipid composition from C24 to C16 increases susceptibility to apoptosis in HeLa cells. Biochim Biophys Acta (2012) 1821:1031-7. doi: 10.1016/j.bbalip.2012.04.008

38. Raichur S, Wang ST, Chan PW, Li Y, Ching J, Chaurasia B, et al. CerS2 haploinsufficiency inhibits beta-oxidation and confers susceptibility to dietinduced steatohepatitis and insulin resistance. Cell Metab. (2014) 20:687-95. doi: 10.1016/j.cmet.2014.09.015

39. Levy M, Futerman AH. Mammalian ceramide synthases. IUBMB Life (2010) 62:347-56. doi: 10.1002/iub.319

40. Schiffmann S, Birod K, Mannich J, Eberle M, Wegner MS, Wanger R, et al. Ceramide metabolism in mouse tissue. Int J Biochem Cell Biol. (2013) 45:188694. doi: 10.1016/j.biocel.2013.06.004

41. Schüll S, Gunther SD, Brodesser S, Seeger JM, Tosetti B, Wiegmann $\mathrm{K}$, et al. Cytochrome $\mathrm{c}$ oxidase deficiency accelerates mitochondrial apoptosis by activating ceramide synthase 6. Cell Death Dis. (2015) 6:e1691. doi: $10.1038 /$ cddis. 2015.62

42. Turpin SM, Nicholls HT, Willmes DM, Mourier A, Brodesser S, Wunderlich $\mathrm{CM}$, et al. Obesity-induced CerS6-dependent C16:0 ceramide production promotes weight gain and glucose intolerance. Cell Metab. (2014) 20:678-86. doi: 10.1016/j.cmet.2014.08.002

43. Hoeferlin LA, Fekry B, Ogretmen B, Krupenko SA, Krupenko NI. Folate stress induces apoptosis via p53-dependent de novo ceramide synthesis and up-regulation of ceramide synthase 6. J Biol Chem. (2013) 288:12880-90. doi: $10.1074 /$ jbc.M113.461798

44. Laviad EL, Kelly S, Merrill AHJr, Futerman AH. Modulation of ceramide synthase activity via dimerization. J Biol Chem. (2012) 287:21025-33. doi: 10.1074/jbc.M112.363580
45. Sassa T, Hirayama T, Kihara A. Enzyme activities of the ceramide synthases CERS2-6 are regulated by phosphorylation in the C-terminal region. J Biol Chem. (2016) 291:7477-87. doi: 10.1074/jbc.M115.695858

46. Breslow DK, Collins SR, Bodenmiller B, Aebersold R, Simons K, Shevchenko A, et al. Orm family proteins mediate sphingolipid homeostasis. Nature (2010) 463:1048-53. doi: 10.1038/nature08787

47. Shimobayashi M, Oppliger W, Moes S, Jeno P, Hall MN. TORC1-regulated protein kinase Nprl phosphorylates Orm to stimulate complex sphingolipid synthesis. Mol Biol Cell (2013) 24:870-81. doi: 10.1091/mbc.e12-10-0753

48. Muir A, Ramachandran S, Roelants FM, Timmons G, Thorner J. TORC2-dependent protein kinase Ypk1 phosphorylates ceramide synthase to stimulate synthesis of complex sphingolipids. Elife (2014) 3:e03779. doi: 10.7554/eLife.03779

49. Heinz LX, Baumann CL, Koberlin MS, Snijder B, Gawish R, Shui G, et al. The Lipid-Modifying Enzyme SMPDL3B Negatively Regulates Innate Immunity. Cell Rep. (2015) 11:1919-28. doi: 10.1016/j.celrep.2015.05.006

50. Kornhuber J, Müller CP, Becker KA, Reichel M, Gulbins E. The ceramide system as a novel antidepressant target. Trends Pharmacol Sci. (2014) 35:293-304. doi: 10.1016/j.tips.2014.04.003

51. Kornhuber J, Tripal P, Reichel M, Mühle C, Rhein C, Muehlbacher M, et al. Functional Inhibitors of Acid Sphingomyelinase (FIASMAs): a novel pharmacological group of drugs with broad clinical applications. Cell Physiol Biochem. (2010) 26:9-20. doi: 10.1159/000315101

52. Park JW, Park WJ, Futerman AH. Ceramide synthases as potential targets for therapeutic intervention in human diseases. Biochim Biophys Acta (2014) 1841:671-81. doi: 10.1016/j.bbalip.2013.08.019

Conflict of Interest Statement: The authors declare that the research was conducted in the absence of any commercial or financial relationships that could be construed as a potential conflict of interest.

The handling Editor declared a shared affiliation, though no other collaboration, with one of the authors MR.

The reviewer KB declared a shared affiliation, with no collaboration, with several of the authors DL, AF, and SR to the handling Editor.

Copyright (C) 2018 Reichel, Rhein, Hofmann, Monti, Japtok, Langgartner, Füchsl, Kleuser, Gulbins, Hellerbrand, Reber and Kornhuber. This is an open-access article distributed under the terms of the Creative Commons Attribution License (CC BY). The use, distribution or reproduction in other forums is permitted, provided the original author(s) and the copyright owner(s) are credited and that the original publication in this journal is cited, in accordance with accepted academic practice. No use, distribution or reproduction is permitted which does not comply with these terms. 